\title{
Improving medical student preparedness for practice in line with the General Medical Council's outcomes for graduates: a pilot study
}

\author{
Authors: Adam Moxley, Lucy Baxter and Phil White
}

\section{Introduction}

The 2018 Outcomes for Graduates ${ }^{1}$ highlight non-technical skills as an important part of what should be expected of an F1 (foundation year 1) doctor. However, studies show that medical school graduates have a relative weakness in these areas. ${ }^{2-4}$

There is a growing body of evidence for simulation as a learning tool in recent years, ${ }^{5}$ however, greater benefits are observed when simulation environment aligns with clinical practice. ${ }^{6}$

Studies have experimented with applying simulation to nontechnical skills ${ }^{7-9}$ with great success; however, application of prolonged and repeated simulation to non-technical skills in medical students has not been studied in detail.

\section{Methods}

Each student was asked to self-assess confidence for the eight outcomes from the Outcomes for Graduates ${ }^{1}$ domain $9 \mathrm{~b}$ on their first day placed at South Tyneside District Hospital. They will then be asked to further self-assess confidence after each intervention designed to meet these outcomes: at the end of the Preparation for Practice module, at the end of their assistantship on the wards, and following a simulated 'day in the life of an F1' session. ${ }^{10}$

This will allow comparison of which interventions helped most to achieve each outcome and whether the combination has allowed all students to increase in confidence for all outcomes.

The Preparation for Practice module involves a prolonged (3-week), low-fidelity simulation in the form of a virtual ward, and the 'day in the life' session is a high-fidelity immersive simulation. This will allow us to also compare simulation with clinical experience as a method to improve final-year preparedness for practice.

Structured interviews will be conducted on completion of the selfassessment survey to gain further qualitative information to help identify reasons behind students' scoring at each stage.

Students completed the low-fidelity virtual ward simulation in December 2018 and completed their assistantship and 'day in the life' simulations in February 2019.

Authors: South Tyneside District Hospital, South Shields, UK

\section{Results}

The results from the low-fidelity Preparation for Practice block in December 2018 have been encouraging. We saw an increase of confidence in all of the eight outcomes from Outcomes for Graduates 9b, with the mean confidence increase across all eight outcomes being $44.5 \%$. One student reported a $250 \%$ increase in their confidence for one particular outcome.

The results for further points of questioning regarding their confidence in the outcomes are pending. We hope to observe further increases in confidence at each stage and compare the difference in increase between simulated interventions and clinical experience. Structured interviews will allow us to explore why some interventions were perceived to increase confidence more than others.

\section{Discussion and conclusions}

Our findings so far suggest that students have engaged deeply with the subject material and feel equipped to put lessons learnt into practice in the ward environment over the next few months. It appears that further innovation and research could explore this method of framing educational courses to improve students' understanding and ability in the skills and attributes required for clinical practice, in particular non-technical skills. We hope this study will provide evidence that specifically targeting these areas significantly improves students' self-assessed preparedness for practice against the Outcomes for Graduates and encourage further work and study in this domain.

\section{References}

1 General Medical Council. Outcomes for graduates 2018. London: GMC, 2018. www.gmc-uk.org/-/media/documents/dc11326outcomes-for-graduates-2018_pdf-75040796.pdf [Accessed 15 January 2019].

2 Illing J, Morrow G, Kergon C et al. How prepared are medical graduates to begin practice? A comparison of three diverse UK medical schools. Final report for the GMC Education Committee. General Medical Council / Northern Deanery, 2008. www.gmc-uk.org/-/ media/about/how-prepared-are-medical-graduates.pdf [Accessed 25 March 2019].

3 Tallentire V, Smith SE, Wylde K, Cameron HS. Are medical graduates ready to face the challenges of Foundation training? Postgrad Med J 2011;87:590-5. 
4 Thomas I, Nicol L, Regan L et al. Driven to distraction: a prospective controlled study of a simulated ward round experience to improve patient safety teaching for medical students. BMJ Qual Saf 2015;24:154-61.

5 Motola I, Devine LA, Chung HS, Sullivan JE, Issenberg SB. Simulation in healthcare education: A best evidence practical guide. AMEE Guide No. 82. Med Teach 2013;35:e1511-30.

6 Sadideen H, Hamaoui K, Saadeddin M, Kneebone R. Simulators and the simulation environment: getting the balance right in simulation-based surgical education. Int J Surg 2012;10:458-62.

7 Cairnduff K, Nagalingam K, Wheeldon A. P14 Simulated 'transition' ward for final year student nurses: developing leadership, management and professional nursing practice in a realistic clinical environment. BMJ Simul Technol Enhanc Learn 2018:4:A58.
8 Ker J, Mole L, Bradley P. Early introduction to interprofessional learning: a simulated ward environment. Med Educ 2003;37:24855.

9 Carpenter C, Parkinson I, Brewster L, Vince G. SC14 'Human factors day': ward simulation for developing medical students' nontechnical skills. BMJ Simul Technol Enhanc Learn 2018:4:A20-1.

10 Baxter L, Manning S. Does the positioning of medical school finals affect preparation for F1? Association for the Study of Medical Education ASM 2016 Abstract Book, 2016. www.asme.org.uk/ images/ASM_2016_ABSTRACTS_FINAL_FOR_WEBSITE.pdf [Accessed 15 January 2019]. 